Islam, M.N. and Sacks, S. 2016. An experimental investigation into the dimensional error of powder-binder three-dimensional printing. International Journal of Advanced Manufacturing Technology. 82 (5-8): pp. 1371-1380. 


\title{
An Experimental Investigation into the Dimensional Error of Powder- Binder Three-Dimensional Printing
}

\begin{abstract}
This paper is an experimental investigation into the dimensional error of the rapid prototyping additive process of powder-binder three-dimensional printing. Ten replicates of a purpose-designed part were produced using a three-dimensional printer, and measurements of the internal and external features of all surfaces were made using a general purpose coordinate measuring machine. The results reveal that the bases of all replicates (nominally flat) have a concave curvature, producing a flatness error of the primary datum. This is in contrast to findings regarding other three-dimensional printing processes, widely reported in the literature, where a convex curvature was observed. All external surfaces investigated in this study showed positive deviation from nominal values, especially in the $z$-axis. The $z$-axis error consisted of a consistent positive cumulative error and a different constant error in different replicates. By compensating for datum surface error, the average total height error of the test parts can be reduced by 25.52\%. All the dimensional errors are hypothesised to be explained by expansion and the subsequent distortion caused by layer interaction during and after the printing process.
\end{abstract}

Keywords - 3D printing, powder-binder printing, additive manufacturing, rapid prototyping, dimensional error

\section{Introduction}


Three-dimensional printing (3DP) is an additive manufacturing process in the field of rapid prototyping (RP) invented by the Massachusetts Institute of Technology in 1993 [1]. This process is used to create three-dimensional (3D) objects through the summation of horizontal ( $x$-y-plane) layers in the vertical (z-axis) direction. These layers are formed in a flat powder bed through the selective projection of a liquid binding agent onto the surface of the powder bed, which solidifies the powder. To achieve this formation, data from a 3D stereolithography file are used to control the distribution of the binder by the inkjet printer head. After each layer is formed, additional powder is spread on top of the previously formed layer, and a roller is used to level this powder to the desired layer thickness. The process is repeated until the 3D object is completed.

The 3DP process developed at MIT was commercialised, and the term 'ThreeDimensional Printing' was trademarked by Z Corporation in 1995 [2]. However, in recent years, the meaning of the term 3DP has expanded to include several other manufacturing processes in which 3D solid objects are made from a digital file. One common characteristic of these processes is creation of parts through layer-by-layer addition of work material; hence, these processes are also known as additive manufacturing (AM). The main differences between various 3DP processes are the way the layers are deposited to create parts and in the materials that are used. Most frequent uses of 3DP processes are: selective laser sintering (SLS), fused deposition modeling (FDM), stereolithography (SLA), powder-binder printing (PBP), and electron beam additive manufacturing (EBAM). The process of powder-binder printing is also known as binder jetting [2, 3] and drop on bed 3DP [4].

The emerging field of 3DP has significant potential in the manufacturing world. In particular, it offers the promise of reduced manufacturing costs and the ability to cut 
lead time and time to market. Although 3DP-processed parts have only been traditionally used as prototypes, its scope of use is continuously broadening as these technologies develop. Today, 3DP is used for tooling, jobbing, casting moulds and many other applications in the bio-medical field. However, a number of issues regarding cost, accuracy, and strength of 3D products need to be overcome before this technology can achieve widespread adoption as pointed out by Berman [5]. Kruth et al., [6] identified the most significant factor inhibiting further manufacturing penetration is the inferior dimensional accuracies of the RP processes. Lee et al., [7] suggested that the dimensional inaccuracy of $3 \mathrm{D}$ printed parts is a direct result of the layer-by-layer manufacturing process and the interaction between adjacent layers.

Investigations on dimensional accuracy achievable by various 3DP processes have received notable attention in the literature. A number of review papers have been published on various 3DP processes [4, 6, 8-12]. A brief review of papers dealing with dimensional accuracy of 3DP-processed parts is presented below.

\subsection{Selective laser sintering}

Senthilkumaran et al., [13] developed a model for shrinkage in SLS and proposed a shrinkage compensation scheme to enhance the accuracy of parts. They reported considerable improvement in the accuracy of the parts applying their compensation scheme. Raghunath and Pandey [14] investigated the shrinkage in SLS and found that the most significant process variables influencing shrinkage are laser power and scan length for $x$ direction, laser power and beam speed for $y$ direction, and beam speed, hatch spacing and part bed temperature for $z$ direction. Singh et al., [15] applied the face centered central composite design response surface methodology for predicting the 
shrinkage of parts produced by SLS process considering five process parameters-laser power, scan spacing, bed temperature, hatch length, and scan count. They concluded that the scan spacing was the most significant parameter influencing the shrinkage. Yang et al., [16] used the Taguchi method for minimising the shrinkage of parts resulting from the phase changes during the SLS process considering 13 input parameters defining the build position. Soe [17] investigated factors affecting the curling of parts produced by SLS and found that the curling is dependent upon a host of input parameters such as part processing parameters, the position of the part in the build chamber, part geometry, part orientation, and the type of materials used. Of the eight processing parameters considered, the powder bed temperature was found to be the most significant factor affecting the curl height.

\subsection{Fused deposition modelling}

Masood and Rattanawong [18] proposed a generic part orientation system for minimizing the amount of volumetric error in the part produced by FDM. Wang et al., [19] developed a mathematical model for the warp deformation of FDM processes, considering the material characteristics, setup of the fabrication parameters, geometrical structure of the CAD model, and deposition path planning. Zhang and Chou [20] applied a finite element analysis (FEA) model to examine the influence of three input parameters—scan speed, layer thickness, and road width on residual stresses and distortions of parts produced by the FDM process and found that scan speed is the most significant factor followed by the layer thickness. The influence of the road width by itself was insignificant; nonetheless, there was considerable interaction between the

road width and the layer thickness. Chang et al., [21] investigated the effects of four extruding parameters - contour width, contour depth, part raster width, and raster 
angle—on quality characteristics of parts produced by FDM process applying Taguchi's method and concluded that the contour width is the most significant factor affecting profile error and aperture area. Tong et al., [22] developed an error compensation method for improving dimensional accuracy of parts produced by FDM by slice file compensation method. Sood et al., [23] applied the Taguchi method and grey relational analysis for improving the dimensional accuracy of FDM build parts considering five process parameters: layer thickness, part build orientation, raster angle, raster to raster gap (air gap), and raster width.

\subsection{Stereolithography}

Lee et al., [24] applied a neural network approach to predict the effects of the input parameters on the dimensional accuracy of part produced by the SLA process and concluded that the layer thickness, hatch overcure, and hatch spacing are the most influentual parameters. Huang and Lan [25] simulated the liquid SLA process by applying dynamic finite element method and reduced dimensional error of final parts through reverse compensation. Zhou et al., [26] applied response surface methodology and Analysis of Variance (ANOVA) to optimize five build parameters, namely, the layer thickness, resultant overcure, hatch space, blade gap, and part location in the SLA. Pham and Ji [27] examined the part model approximation errors and the part building and finishing errors in SLA and proposed three design rules for eliminating or at least reducing the errors. Jayanthi et al., [28] applied ANOVA to investigate the effects of process parameters, such as layer thickness, writing style, hatch spacing, hatch over cure, and fill cure depth on curl distortion in SLA-printed parts. 


\subsection{Powder-binder printing}

Dimitrov et al., [29] examined the dimensional and geometric accuracies of the PBP process and found that they were influenced by three major factors: powder material, build orientation, and the magnitude or the nominal dimension. Ollison and Berisso [30] studied the effects of build orientation, print head life, and the diameter of the 3D printed part on their cylindricity and concluded that build orientation was the only parameter to have a significant effect on the cylindricity of 3D printed parts. Hsu and Lai [31] applied the Taguchi method for improving the dimensional accuracy of 3D green parts considering four process parameters: layer thickness, binder setting saturation value, shell and core, and location of green parts. Suwanprateeb et al., [32] studied the influence of changing printing parameters (powder layer thickness and binder saturation) in a PBP machine on the transformation of a PBP printed plaster of Paris to hydroxyapatite by low-temperature-phosphorisation and found that printing parameters strongly affected the transformation efficiency and properties of the samples. Islam et al., [33] examined variations in length, width, height, and hole diameter of parts produced by PBP and found that inherent size errors were associated with the PBP process.

\subsection{Electron beam additive manufacturing}

Liu et al., [34] developed a mathematical modelling for assessing geometric errors of EBAM. The model considered the errors generated in both the data preparation process, (slicing error) and the part-building process (the effects of surface tilting, layer thickness variation and profiling errors in each layer, and error transformation between the layers). They validated their model by comparing estimated error with measured 
error and reported 5.5\% difference for the location error and $19.5 \%$ difference for dimensional errors. Cooke and Soons [35] analysed the variability in the geometric accuracy of a metal test part manufactured by a number of service providers using EBAM and laser beam powder bed thermal fusion processes. They observed that errors of the AM parts were significantly larger than those of typical machined parts; however, the errors showed a high level repeatability indicating possible development of compensation strategies by predicting the magnitudes of the errors.

From the available literature review, it is evident that a reasonable base of knowledge exists that compares the dimensional accuracy between 3DP technology and other RP processes. In addition, the influence that a number of process variables have on the overall dimensional accuracy of 3DP has been analysed. An understanding of material distortion in other 3DP processes has been well established in the literature with common shrinkage and "curling” phenomena. In the field of PBP, however, little has been done to quantify part inaccuracy and understand the nature of the material distortion that occurs. In this paper, an attempt has been made to explore and quantify the dimensional error that exists in PBP, with emphasis on the datum surface and linear dimensions.

\section{Experimental Work}

A simple test part was designed for the experimental purpose (Figure 1), which was to provide an independent analysis of various aspects of the linear dimensional error of PBP. The test part consisted of multiple concentric cylinders of reducing radii on top of each other with a central hole of a uniform diameter. The isosymmetric shape was chosen so that volumetric change during part creation is uniform in all directions which is easier to analyse. Having a five different heights evident in the part geometry allowed 
numerous height measurements to be taken for each replicate, reducing the number of replicates required. The base diameter and the maximum height of the test part were 126 $\mathrm{mm}$ and $60 \mathrm{~mm}$, respectively. The base surface of the test part was considered the primary datum and the hole axis was considered the secondary datum.

Ten replicates of the test part were produced in a Z450 3D printer manufactured by $\mathrm{Z}$ Corporation (USA). The 3D printer was a multicolour one especially designed for everyday use in a standard office environment. The printer has a specific resolution of 300 dpi $\times 450$ dpi and a $203 \mathrm{~mm} \times 254 \mathrm{~mm} \times 203 \mathrm{~mm}$ build size. The printer enables the selection of a build layer thickness between $0.089 \mathrm{~mm}$ and $0.102 \mathrm{~mm}$; the selected build layer thickness was the default setting of $0.1016 \mathrm{~mm}$. Specifications of the 3D printer used in this study can be found in [36]. The material used for the fabrication of the part was high-performance composite powder Z150 (calcium sulfate hemihydrate, better known as plaster of Paris) with water-based clear binder solution zb63 (2-pyrrolidone).

A general purpose coordinate measuring machine (Discovery model D-8, Shefield, U.K.) was used to measure the green (untreated) parts. It has 0.1 micron position resolution with axial repeatability of measurement of \pm 2.5 micron within its full travel area. A spherical probe $4 \mathrm{~mm}$ in diameter (Renishaw Electrical Ltd., U.K.) was used, and it touched various locations of the part to collect data for the hole diameter, outer diameter, height, and base geometry. The primary datum of the part was place on the flat granite table of the CMM and all $z$ direction measurements were taken from the granite table. Details of the locations for each measurement are shown in Figure 2. To measure height, the probe touched the top surface of each cylinder at eight locations with a specified radius. This measurement was completed three times at three different radii for each top surface. To obtain the surface topography of the bottom surface, the 
part was placed upside down on a fixture and using the aligning capability of the CMM a surface plane was established parallel to the granite table probing three points of the bottom surface the test part. Then 80 points were probed as shown in Figure 2. For the hole diameter, numerous measurements were taken at $1 \mathrm{~mm}$ increments along the height by probing eight different locations around the circumference within each diameter. Similar measurements were taken for the external diameter of each cylinder. These measurements were taken at eight different locations on each cylinder's circumference, with three equidistant height variations on each cylinder.

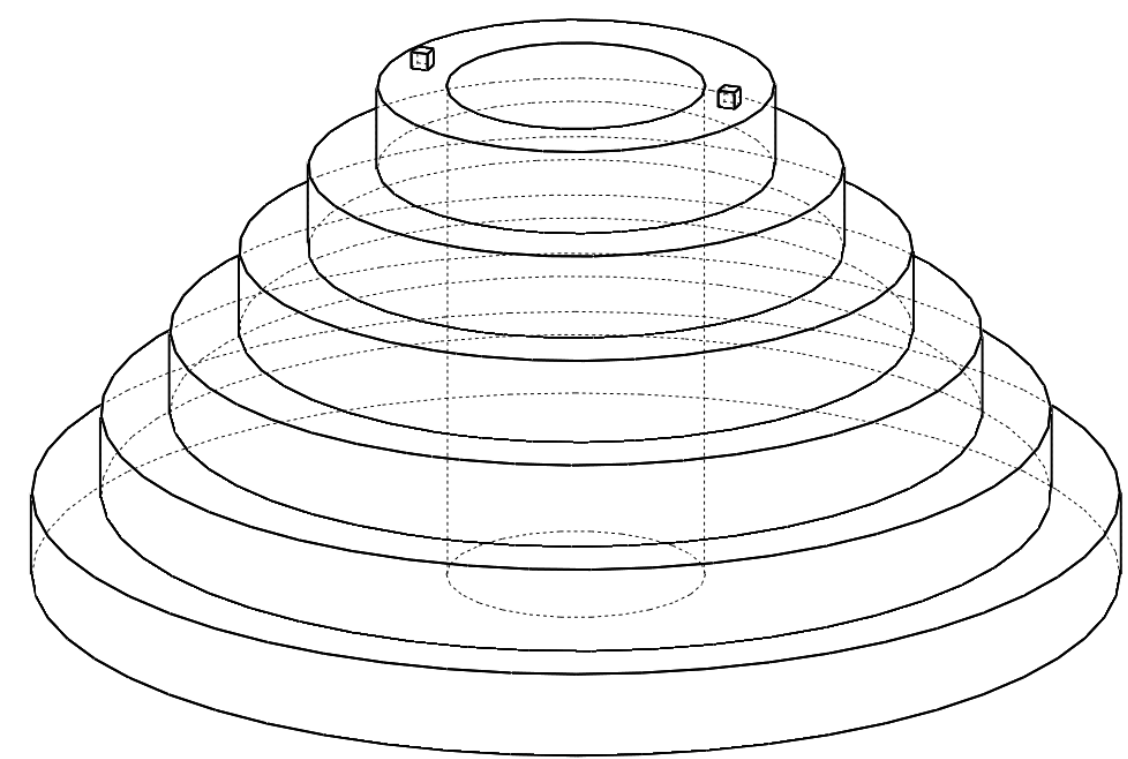

Figure 1: Three-dimensional sketch of the test part 

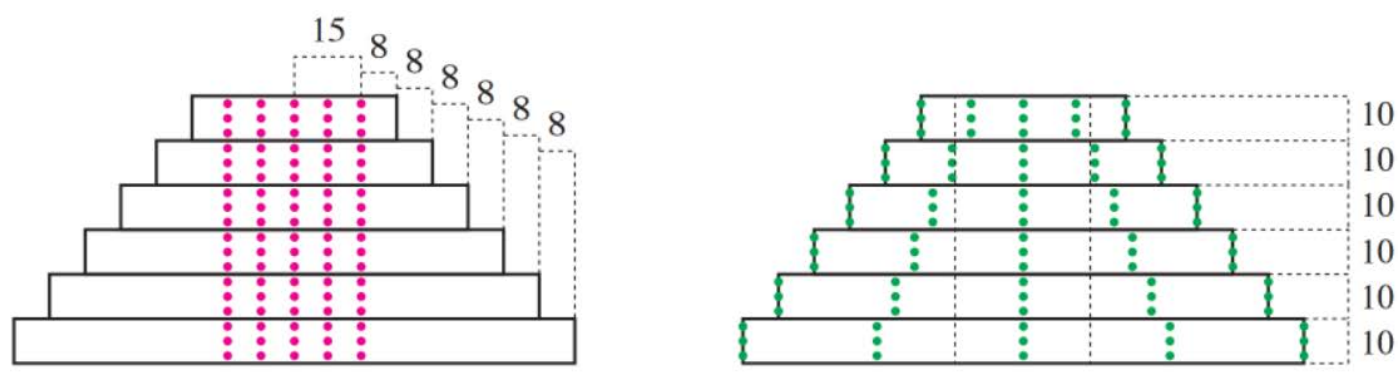

T O P

B O T T O M
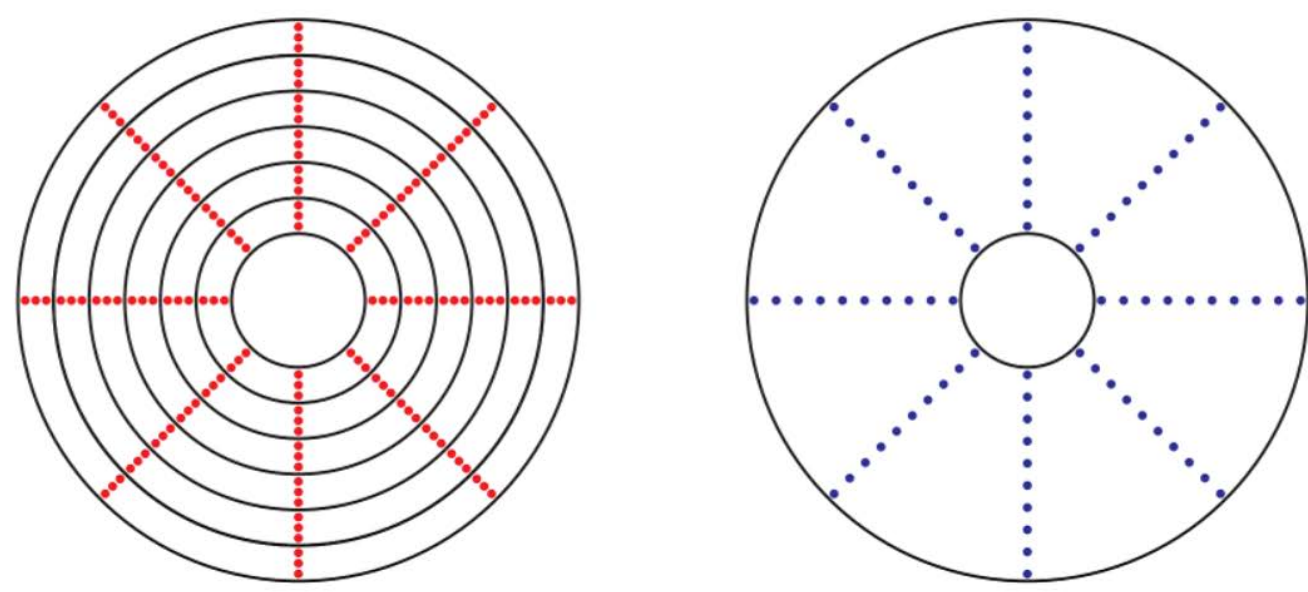

- Bore diameter probe location

- Outer diameter probe location

- Height probe location

- Bottom surface probe location

Figure 2: Probe locations for each measurement (all dimensions are in mm)

\section{Results}

\subsection{Datum surface error}

Dimensional accuracy of any part is significantly influenced by the accuracy of datum surface as all dimensions refer to it. Consequently, a flatness tolerance is typically 
imposed on the datum surface. Therefore, a detailed examination of the datum (bottom) surface of the test parts was performed. Figure 3 shows the datum surface error for each part, which varies between $0.120 \mathrm{~mm}$ and $0.395 \mathrm{~mm}$, with an average value of 0.255 $\mathrm{mm}$. Note that this flatness error contributes error in all dimensions taking in the $z$ direction.

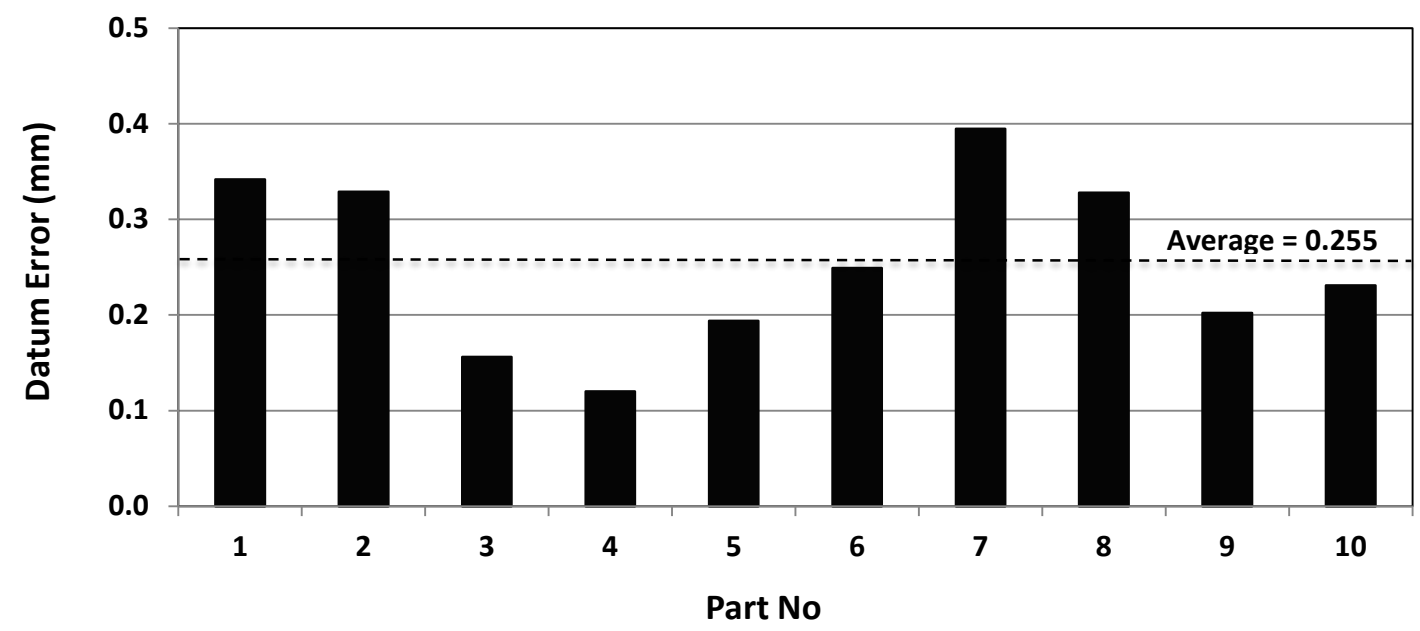

Figure 3: Datum surface error

A close examination of the datum surface reveals a concave curvature that causes the flatness error of the primary datum. An accentuated representation of the datum surface is presented in Figure 4. The results of the average datum surface measurement are given in Figure 5. The height from the lowest point decreases with the increase in distance from the hole axis. 


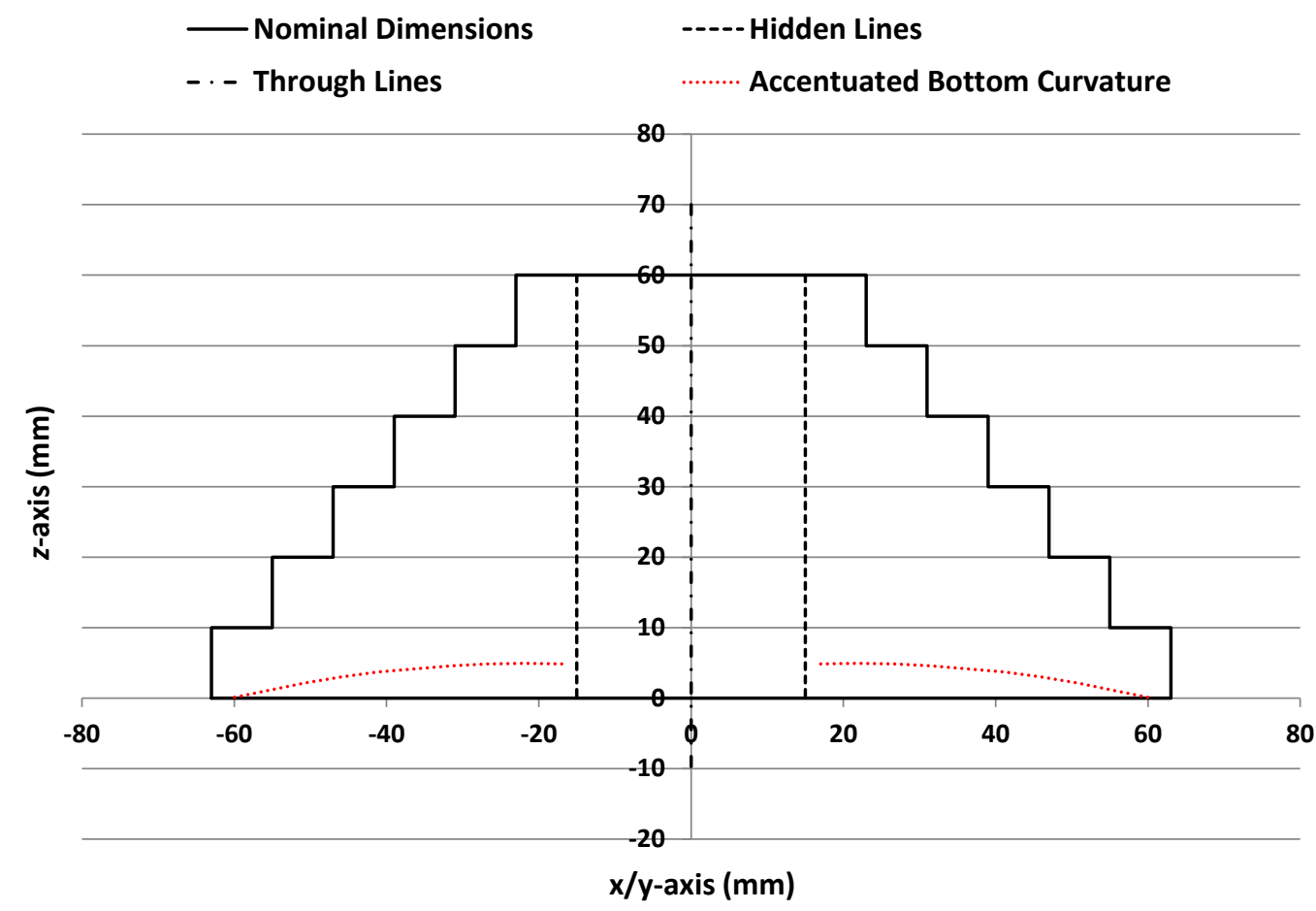

Figure 4: Accentuated representation of the datum surface curvature

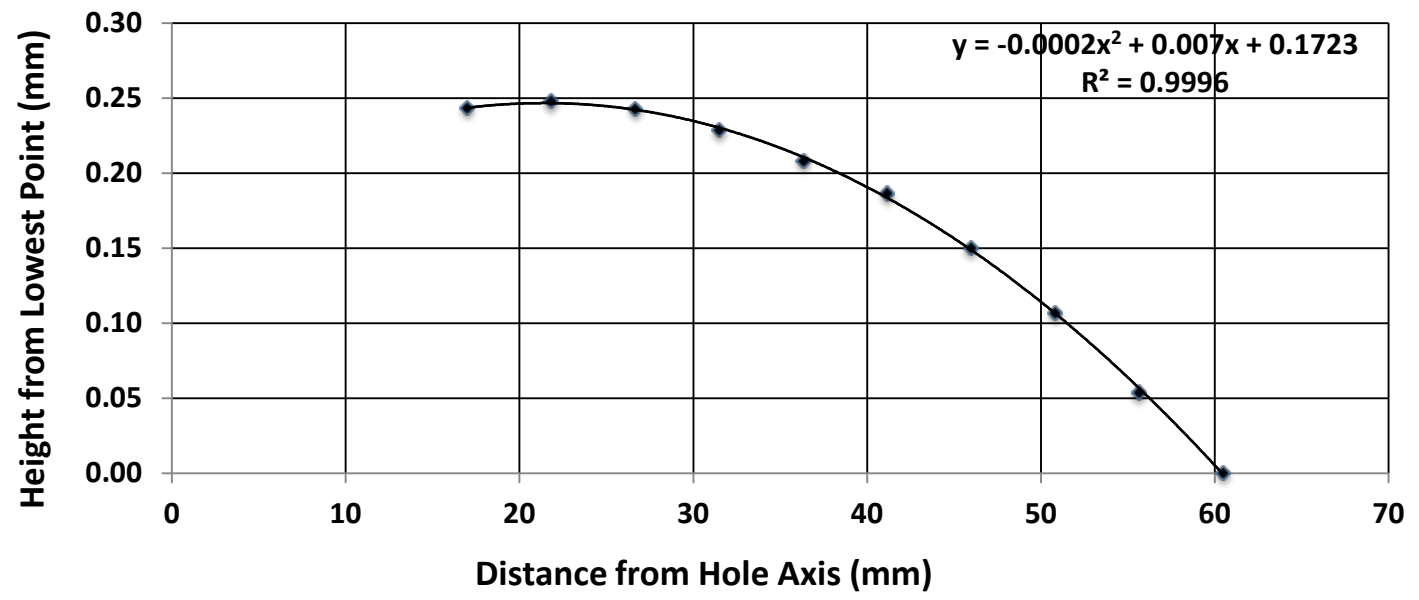

Figure 5: Datum surface measurement results

\section{$3.2 \mathrm{z}$ direction error}


Figure 6 shows the average error for the total height $(60 \mathrm{~mm})$ of each part, which varies between $0.771 \mathrm{~mm}$ and $1.167 \mathrm{~mm}$, with an average value of $0.999 \mathrm{~mm}$. Note that in terms of its height, all parts are oversized. The oversizing occurs not only for the total height but for each height taken at the $10 \mathrm{~mm}$ step. An accentuated representation of height error is presented in Figure 7.

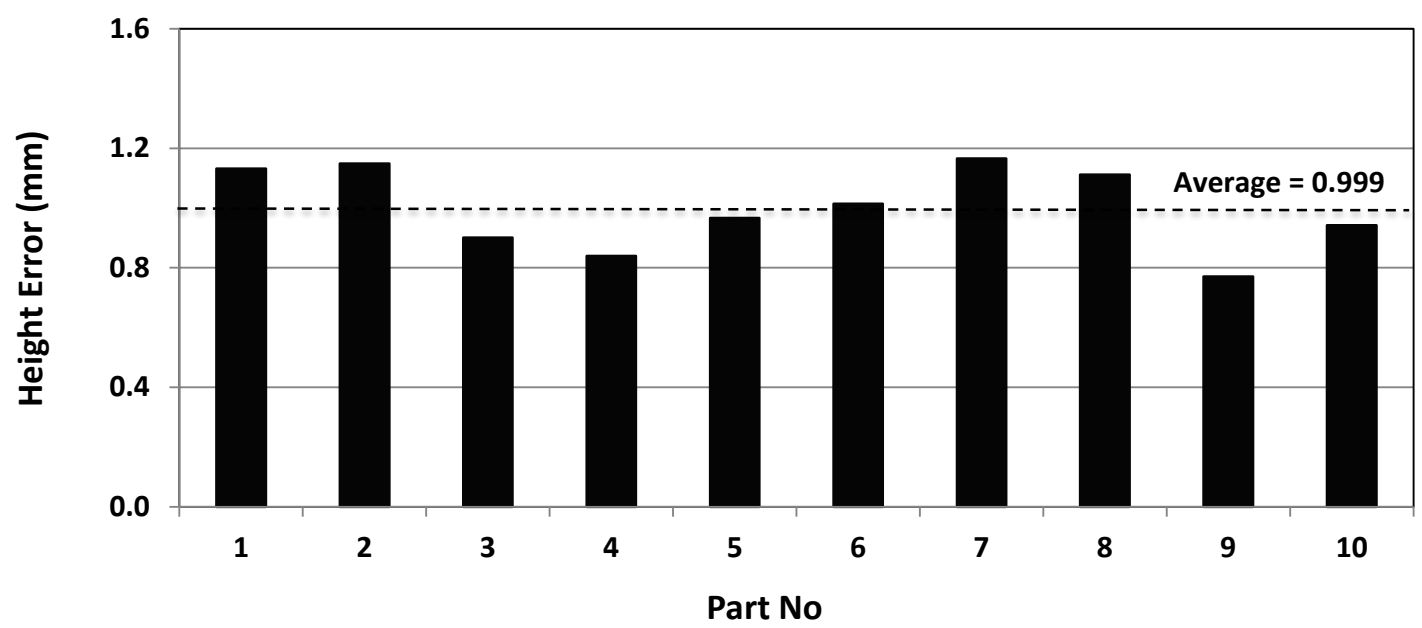

Figure 6: Height error

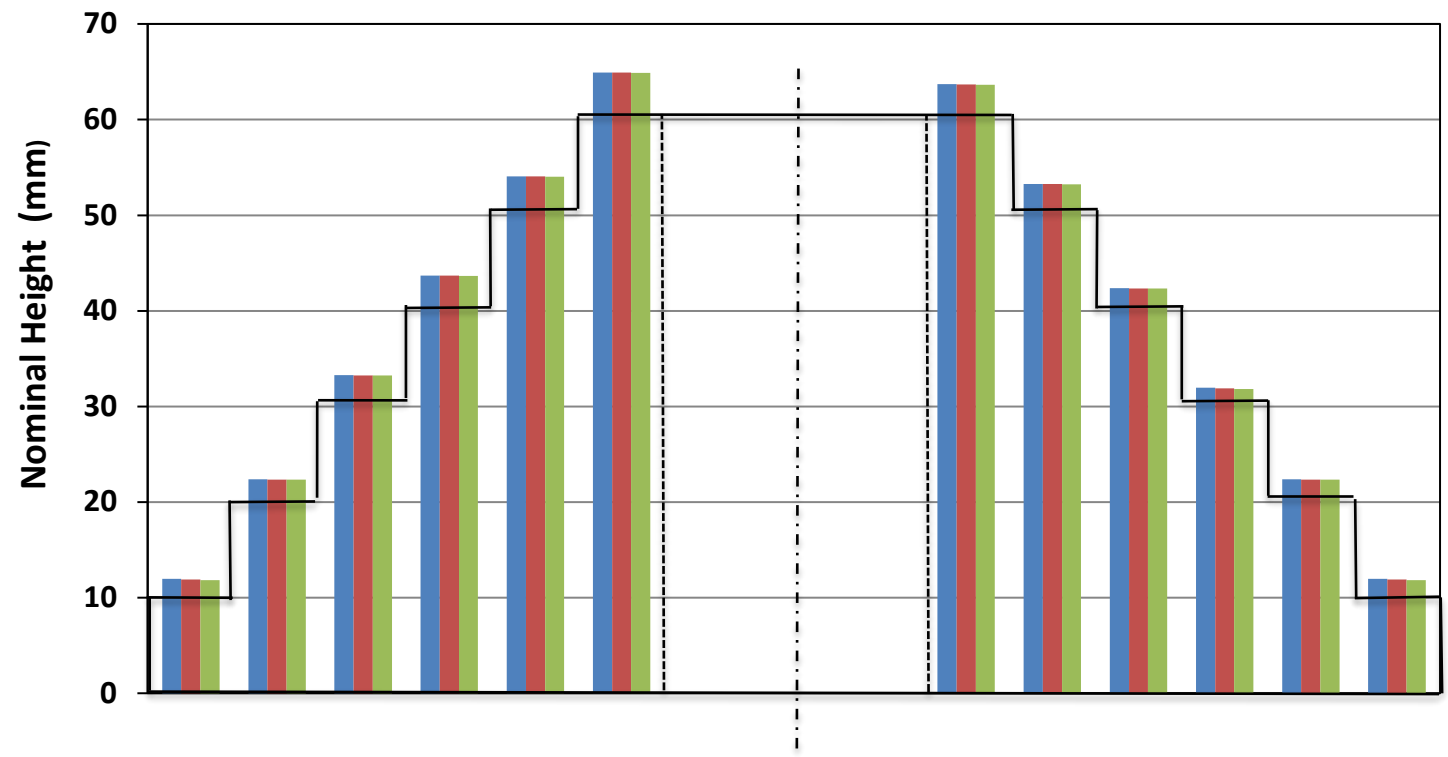


Figure 7: Accentuated representation of height error

For all parts, the height error increases with the increase in nominal height. Only three examples are shown in Figure 8 to avoid confusion. Figure 9 shows the average change in height error with nominal height and its trend line. As shown in the figure, the height error consists of two components: constant error and cumulative error. The cumulative error, represented by the slope of the trend line, is relatively uniform. The constant error, represented by the height of the vertical shift of the curve or the datum error, is not uniform and varies significantly between replicates (Figure 3). The breakdown of the height error for three different heights is illustrated in Figure 10. The total height error increases with the increase in height, indicating its accumulative nature.

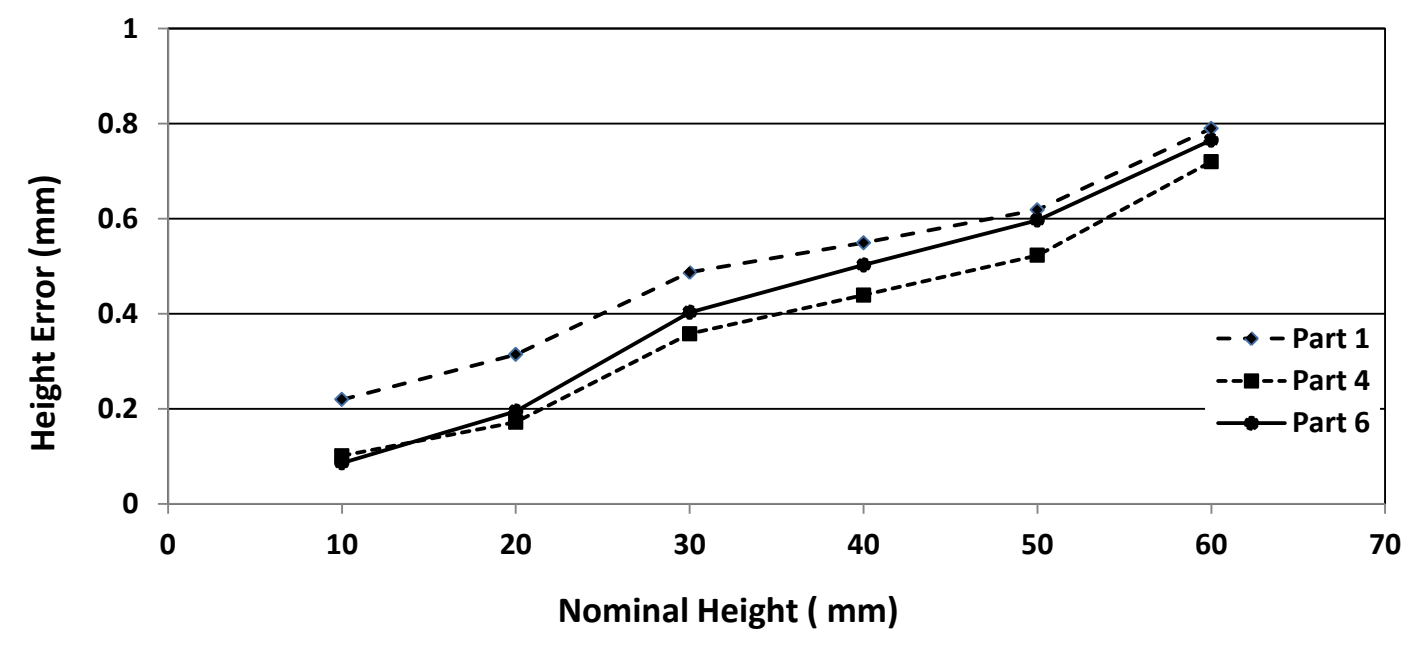

Figure 8: Change in height error with nominal height 


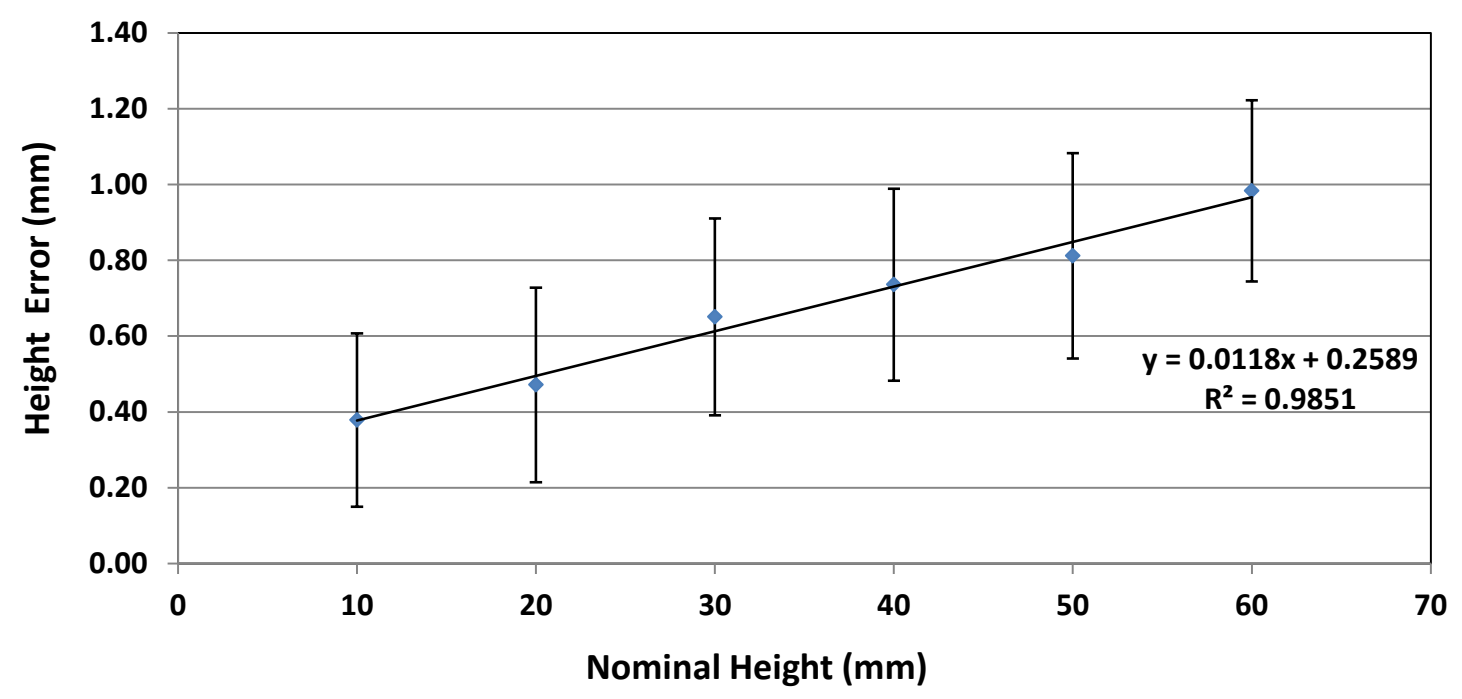

Figure 9: Average change in height error with nominal height 


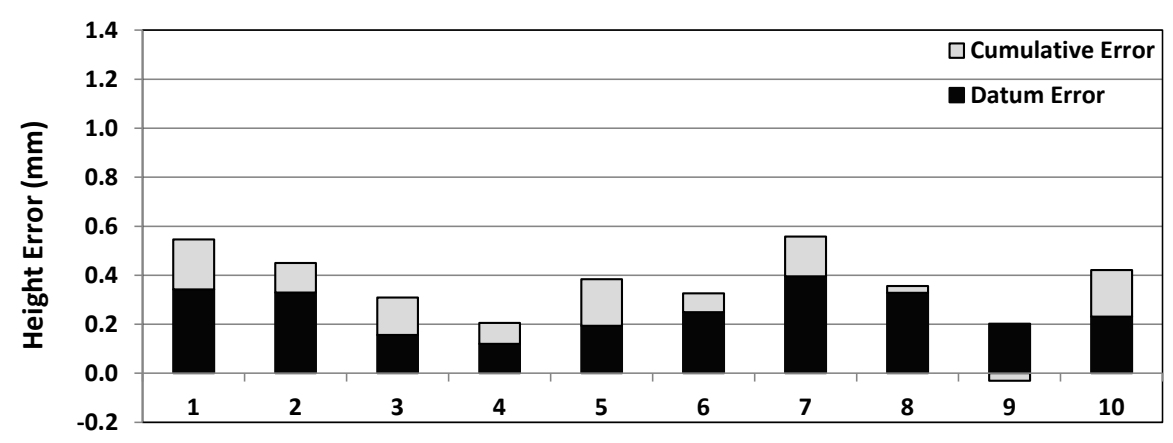

Part No

(a) $z=10 \mathrm{~mm}$

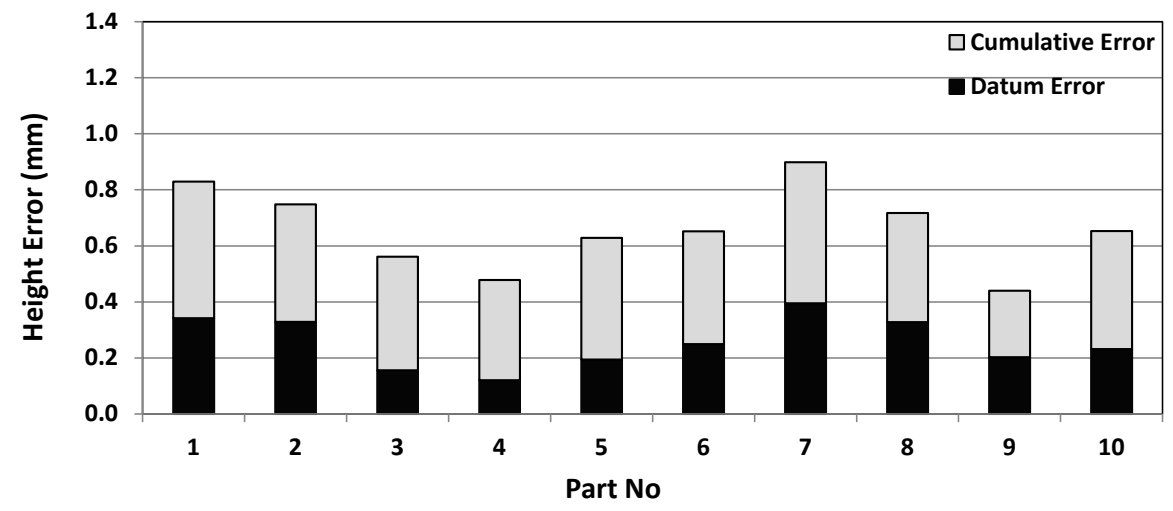

(b) $z=30 \mathrm{~mm}$

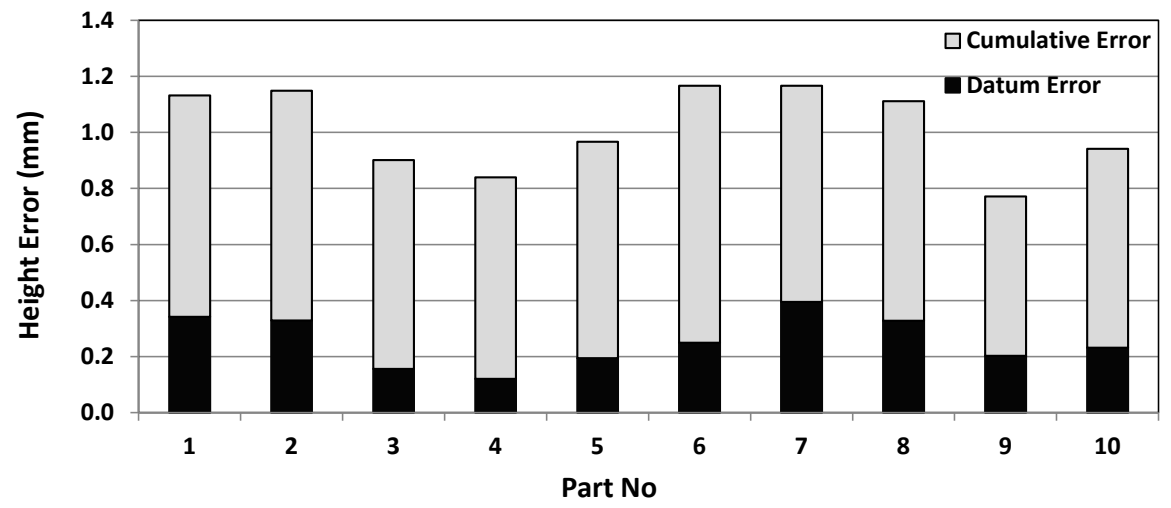

(c) $z=60 \mathrm{~mm}$

Figure 10: Breakdown of height error 


\section{$3.3 x-y$ direction error}

The average deviation from the nominal values of the hole diameter of the 10 replicates is shown in Figure 11. Note that the average hole diameter is consistently undersized. The amount of hole error varies between $-0.156 \mathrm{~mm}$ and $-0.008 \mathrm{~mm}$, with an average value of $-0.068 \mathrm{~mm}$.

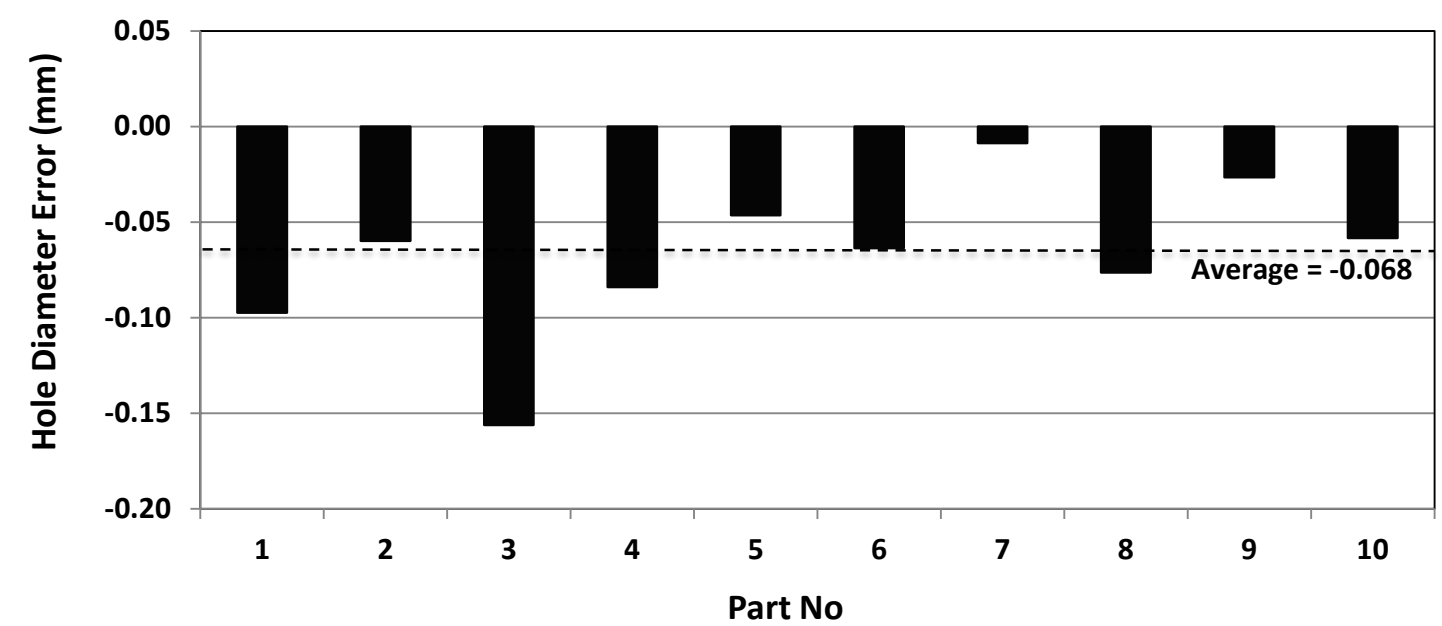

Figure 11: Hole diameter error

Figure 12 shows the average hole profile, where $\mathrm{z}=0$ represents the bottom of the test part (datum surface). The figure shows that, initially, the diameter increases with the height and then starts to decrease. The minimum hole size is reached at the top. The hole is undersized throughout the height. 


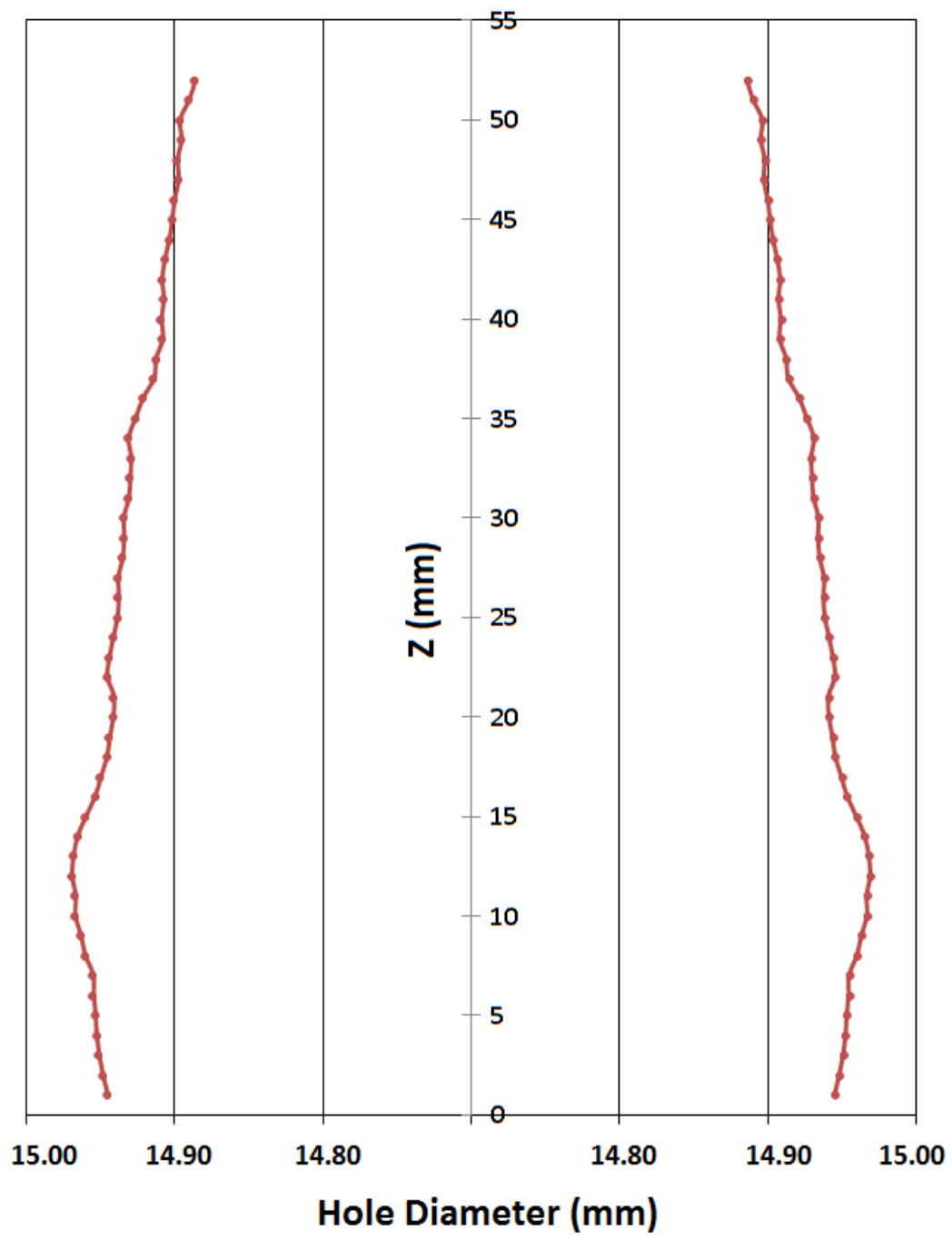

Figure 12: Average hole profile

Figure 13 shows the average error for the outer diameter of the base cylinder (126 mm in diameter) for each part, which varies between $0.007 \mathrm{~mm}$ and $0.058 \mathrm{~mm}$, with an average value of $0.031 \mathrm{~mm}$. The outer diameters were oversized. The relationship between the outer diameter error and the nominal values of the diameter or height was inconclusive. Note that the magnitudes of the $x$-y direction errors (Figures 11 and 13) were considerably less than the magnitude of the $z$ direction error (Figure 6). 


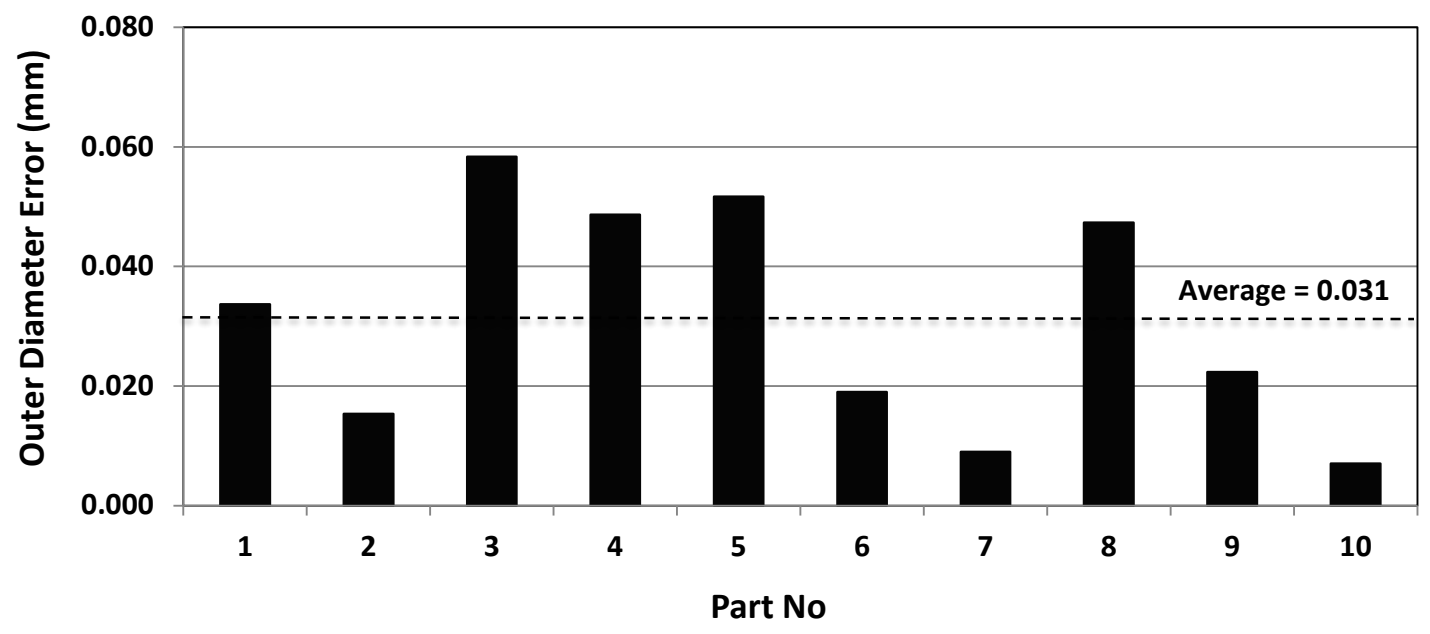

Figure 13: Outer diameter error

\section{Analysis and Discussion}

One of the major findings of this study is the revelation of a concave curvature of the datum surface of all printed parts. This curvature is a major problem in PBP, as the flatness error created by this curvature directly contributes to all dimensions in the zaxis. Therefore, the smaller the height of the feature is, the higher the percent contribution of this error to the total error (Figure 3). By compensating for the datum surface error, the average total height error of the test parts can by reduced from 0.999 $\mathrm{mm}$ to $0.744 \mathrm{~mm}$, a reduction of $25.52 \%$. However, the datum surface error varies between replicates, and further research should be conducted to determine the factors affecting it and to develop a predictive model.

All the dimensions in the $z$ direction are oversized, consistent with the previous findings such as in [33]. This positive error is believed to be associated with the layer-by-layer construction of parts in the PBP process. This study also shows that the height error has two components: constant and cumulative error. A linear relationship between the 
cumulative error and the nominal height is established (Figure 9). Therefore, the compensation of the cumulative error is relatively easy. However, the slope of this linear relationship may depend on various factors, and further research is needed to establish it.

The outer diameters measured in the x-y-plane are oversized. However, the relationship between the outer diameter error and the nominal values of the diameter or the height is inconclusive because step cylinders were used in our experiment. The diameter change and the height change occur concurrently. Consequently, the $x-y$ direction error is confounded with the $z$ direct error.

The overall volumetric expansion was found to occur in all dimensions, accompanied with a variable extent of the concave curvature on the datum surface of the replicates. It is well known that the gypsum $\left(\mathrm{CaSO}_{4} \cdot 2 \mathrm{H}_{2} \mathrm{O}\right)$ solution used in the present work undergoes a phenomenon known as "hygroscopic expansion" upon setting in the presence of water which results in the component expanding by anywhere from a few $0.1 \%$ to greater than $2 \%$ upon setting $[37,38]$ which is in contrast to most materials used for 3D printing in which the built up layers tend to shrink upon setting. The curvature on the datum surface is believed to be caused by the different rates of volumetric expansion between layers, causing a torsional force. We hypothesise that these different rates of expansion are due to the time delay between the formation of the consecutive layers and the rapid, initial expansion of newly formed layers. Moreover, the different rates of expansion of the consecutive layers cause a tethering force, thus restricting the horizontal expansion and creating a cumulative vertical expansion. 
Finally, the following formula [39, 40] based on the tolerance standards for cylindrical fits was applied to estimate the process capability tolerance achievable through PBP:

$$
P C=(0.45 \sqrt[3]{X}+0.001 X) 10^{\frac{I T-16}{5}}
$$

where $P C$ is the process capability tolerance $(\mathrm{mm}), X$ is the manufactured dimension $(\mathrm{mm})$ and $I T$ is the IT grade number.

In Table 1, a comparison of the dimensional error results for three manufacturing processes, namely, CNC end milling, wire-cut discharge machining and 3DP, is presented using data from [41, 42]. The calculated values show that 3DP performed poorly in terms of dimensional accuracy. Dimitrov et al., [29] reported the IT grade for PBP between IT9 and IT15. For direct digital manufacturing (i.e., making finished products directly from CAD files) or for rapid tooling (i.e., making tools for other manufacturing processes such as patterns for the casting process), the level of dimensional accuracy of 3DP needs to be improved.

Table 1: Comparison of Dimensional Errors

\begin{tabular}{llllllll}
\hline \multirow{2}{*}{ Input parameters } & \multirow{2}{*}{ Unit } & \multicolumn{2}{l}{ End Milling [41] } & \multicolumn{2}{l}{ WEDM [42] } & PBP \\
\cline { 3 - 8 } & Length & Width & Length & Width & Height & Width \\
\hline Design size & $\mathrm{mm}$ & 200 & 75 & 20 & 10 & 60 & 126 \\
Measured mean size & $\mathrm{mm}$ & 199.996 & 74.963 & 19.787 & 9.902 & 60.999 & 126.010 \\
Dimensional error & $\mu \mathrm{m}$ & -34 & -37 & -213 & -98 & 999 & 10 \\
6 x Standard deviation & $\mu \mathrm{m}$ & 51 & 53 & 146 & 136 & 931 & 453 \\
IT grade & & 7.277 & 8.146 & 11.713 & 11.365 & 14.543 & 12.386 \\
\hline
\end{tabular}

\section{CONCLUSION}


In summary, findings of an experimental investigation are presented, illustrating the nature of the error found in PBP process and a hypothesis on the causes of these errors. The major findings of this study are as follows:

- The existence of a concave curvature of the datum surface of parts printed from the PBP;

- The identification of the two separate sources of $z$-axis dimensional errors, namely constant and cumulative error components;

- The variability of the datum surface error among identical replicates; and

- The similarity in magnitude of the constant z-axis error of each part replicate and its corresponding height of curvature.

This study shows great potential for future work in dimensional error avoidance and compensation.

\section{REFERENCES:}

1. Printing of the Paper, MITnews, http://newsoffice.mit.edu/2011/3d-printing-0914, September 14, 2011, (accessed on 10/06/2015)

2. 3D printing, http://3dprinting.com/what-is-3d-printing/ (accessed on 10/06/2015)

3. Gibson I, Rosen D, Stucker B (2015) Additive Manufacturing Technologies, Chapter 8, Binder Jetting, $2^{\text {nd }}$ ed. ISBN 978-1-4939-2112-6, Springer Science and Business Media, New York.

4. Levy GN, Schindel R, Kruth JP (2003) Rapid manufacturing and rapid tooling with layer manufacturing (LM) technologies, state of the art and future perspectives. CIRP AnnalsManufacturing Technology, 52(2), 589-609.

5. $\quad$ Berman B (2012) 3-D printing: The new industrial revolution. Business horizons, 55(2), 155-162.

6. Kruth JP, Leu MC, Nakagawa T (1998) Progress in additive manufacturing and rapid prototyping. CIRP Annals-Manufacturing Technology, 47(2), 525-540.

7. Lee SJ, Sachs E, Cima M (1995) Layer position accuracy in powder-based rapid prototyping. Rapid Prototyping Journal, 1(4), 24-37.

8. Relvas C, Ramos A, Completo A, Simões JA (2012) A systematic approach for an accuracy level using rapid prototyping technologies. Proceedings of the Institution of Mechanical Engineers, Part B: Journal of Engineering Manufacture, 226(12), 2023-2034.

9. Melchels FP, Feijen J, Grijpma DW (2010) A review on stereolithography and its applications in biomedical engineering. Biomaterials, 31(24), 6121-6130.

10. Yan X, Gu PENG (1996) A review of rapid prototyping technologies and systems. ComputerAided Design, 28(4), 307-318.

11. Kulkarni P, Marsan A, Dutta D (2000) A review of process planning techniques in layered manufacturing. Rapid Prototyping Journal, 6(1), 18-35. 
12. Gong X, Anderson T, Chou K (2014) Review on powder-based electron beam additive manufacturing technology. Manufacturing Review, 1, 2.

13. Senthilkumaran K, Pandey PM, Rao PVM (2009) New model for shrinkage compensation in selective laser sintering. Virtual and Physical Prototyping, 4(2), 49-62.

14. Raghunath N, Pandey PM (2007) Improving accuracy through shrinkage modelling by using Taguchi method in selective laser sintering. International journal of machine tools and manufacture, 47(6), 985-995.

15. Singh S, Sharma VS, Sachdeva A (2012) Optimization and Analysis of Shrinkage in Selective Laser Sintered Polyamide Parts. Materials and Manufacturing Processes, 27(6), 707-714.

16. Yang HJ, Hwang PJ, Lee SH (2002) A study on shrinkage compensation of the SLS process by using the Taguchi method. International Journal of Machine Tools and Manufacture, 42(11), 12031212.

17. Soe SP (2012) Quantitative analysis on SLS part curling using EOS P700 machine. Journal of Materials Processing Technology, 212(11), 2433-2442.

18. Masood SH, Rattanawong W (2002) A generic part orientation system based on volumetric error in rapid prototyping. The International Journal of Advanced Manufacturing Technology, 19(3), 209-216.

19. Wang TM, Xi JT, Jin Y (2007) A model research for prototype warp deformation in the FDM process. The International Journal of Advanced Manufacturing Technology, 33(11-12), 10871096.

20. Zhang, Y., \& Chou, K. (2008). A parametric study of part distortions in fused deposition modelling using three-dimensional finite element analysis. Proceedings of the Institution of Mechanical Engineers, Part B: Journal of Engineering Manufacture, 222(8), 959-968.

21. Chang DY, Huang BH (2011) Studies on profile error and extruding aperture for the RP parts using the fused deposition modeling process. The International Journal of Advanced Manufacturing Technology, 53(9-12), 1027-1037.

22. Tong K, Joshi S, Amine Lehtihet E (2008) Error compensation for fused deposition modeling (FDM) machine by correcting slice files. Rapid Prototyping Journal, 14(1), 4-14.

23. Sood AK, Ohdar RK, Mahapatra SS (2009) Improving dimensional accuracy of fused deposition modelling processed part using grey Taguchi method. Materials \& Design, 30(10), 4243-4252.

24. Lee SH, Park WS, Cho HS, Zhang W, Leu MC (2001) A neural network approach to the modelling and analysis of stereolithography processes. Proceedings of the Institution of Mechanical Engineers, Part B: Journal of Engineering Manufacture, 215(12), 1719-1733.

25. Huang YM, Lan HY (2005) Dynamic reverse compensation to increase the accuracy of the rapid prototyping system. Journal of materials processing technology, 167(2), 167-176.

26. Zhou JG, Herscovici D, Chen CC (2000) Parametric process optimization to improve the accuracy of rapid prototyped stereolithography parts. International Journal of Machine Tools and Manufacture, 40(3), 363-379.

27. Pham D., Ji, C (2000) Design for stereolithography. Proceedings of the Institution of Mechanical Engineers, Part C: Journal of Mechanical Engineering Science, 214(5), 635-640.

28. Jayanthi S, Keefe M, Gargiulo EP (1994, August) Studies in stereolithography: influence of process parameters on curl distortion in photopolymer models. In Solid Freeform Fabrication Symposium 1994 (pp. 250-258). University of Texas, Austin.

29. Dimitrov D, Van Wijck W, Schreve K, De Beer N (2006) Investigating the achievable accuracy of three dimensional printing. Rapid Prototyping Journal, 12(1), 42-52.

30. Ollison T, Berisso K (2010) Three-dimensional printing build variables that impact cylindricity. J. Ind. Technol, 26(1), 2-10.

31. Hsu TJ, Lai WH (2010) Manufacturing parts optimization in the three-dimensional printing process by the Taguchi method. Journal of the Chinese Institute of Engineers, 33(1), 121-130.

32. Suwanprateeb J, Thammarakcharoen F, Wasoontararat K, Suvannapruk W (2012) Influence of printing parameters on the transformation efficiency of 3D-printed plaster of Paris to hydroxyapatite and its properties. Rapid Prototyping Journal, 18(6), 490-499.

33. Islam MN, Boswell B, Pramanik A (2013, July) An Investigation of Dimensional Accuracy of Parts Produced by Three-Dimensional Printing. In Proceedings of the World Congress on Engineering (Vol. 1, pp. 3-5).

34. Liu W, Li L, Kochhar AK (1998) A method for assessing geometrical errors in layered manufacturing. Part 2: Mathematical modelling and numerical evaluation. The International Journal of Advanced Manufacturing Technology, 14(9), 644-650. 
35. Cooke AL, Soons JA (2010, August) Variability in the geometric accuracy of additively manufactured test parts. In $21^{\text {st }}$ annual international solid freeform fabrication symposium, Austin, Texas, USA (pp. 1-12).

36. 3D Systems, Z Printer 450: Technical Specifications, http://www.zcorp.com/en/Products/3DPrinters/ZPrinter-450/Technical- Specifications154/ spage.aspx (accessed on 10/06/2015)

37. Mahler DB, Ady AB (1960) An explanation for the hygroscopic setting expansion of dental gypsum products. Journal of dental research, (39), 578-89.

38. Michalakis KX, Stratos A, Hirayama H, Pissiotis AL, Touloumi F (2009) Delayed setting and hygroscopic linear expansion of three gypsum products used for cast articulation. The Journal of prosthetic dentistry, 102(5), 313-318.

39. Bjørke Ø (1989) Computer-Aided Tolerancing, The American Society of Mechanical Engineers, New York.

40. Farmer LE (1999) Dimensioning and Tolerancing for Function and Economic Manufacture, Blue Publ., Sydney.

41. Islam MN (1995, November) A CMM-based geometric accuracy study of CNC end milling operations. In Proceedings of $6^{\text {th }}$ Int. Conference on Manufacturing Engineering, Melbourne, 835842.

42. Islam MN, Rafai NH, and Subramaniam SS (2011) Dimensional Accuracy Achievable in Wire-cut Electrical Discharge Machining, in, Electronic Engineering and Applied Computing, Ao, S-L. and Gelman, L. (Eds) Lecture Notes on Electrical Engineering 90, Chapter 43, Springer, Netherlands, 543-553. 